\title{
Construction of System Work Platform of Graduation Desing of the Mechanical and Electronic Profession
}

\author{
Zhiping Yang \\ Chongqing college of electronic engineering \\ Chongqing China 401331 \\ yzp@cqnu.edu.cn
}

\author{
Xiaoyan Liu \\ Chongqing college of electronic engineering \\ Chongqing China 401331 \\ zhoubinlxy @yahoo.com.cn
}

\begin{abstract}
Graduation design of the higher vocational colleges students is an important link to train skilled talents. According to serious quality problem in the graduation design, this study given the methods to select graduation design topic based on the practical environment, constructed the system work platform of the graduate design of the higher vocational students, it improves cultivation mechanism for the skilled talents. The achievements show that applying this platform solved exist serious problems in the electromechanical profession graduation design. Research contributions are suit for same higher vocational colleges as referenced to cultivate skilled talents.
\end{abstract}

Keywords_practical environment ; skilled talents ; graduation design; system working platform

\section{INTRODUCTION}

In chongqing economy, such as cars, motorcycles, equipment manufacturing and other traditional and pillar industries, and the rapid development of electronic information industry, those drive incremental demand for the professional technical talents in the machinery-electric integration, electrical automation and numerical control technology. Because of these urgent needs, how to build the platform of training on the professional skill talents, to complete the mechanism of the talent supplied and demand, to promote the capacity of the professional services in the industry, all these attracted the great attention of the nation and the region, and which are also big challenges for the educational staffs [1] [2].

Graduation design is an important link to train skilled talents. But in this link, higher vocational colleges exist serious problem, in students' graduation design, plagiarised phenomenon of the graduation theses are serious; Furthermore, some students used method of the coping and the pasting to form summary literary or graduation designs directly, using few hours, they completed the graduation design task, while the tasks are completed needed for a few months practice; These behaviors, not only affect seriously the quality of the graduation design, even the basic requirements of graduation design can not be reached, role of the graduation design link is very limited to cultivate senior skilled talents, this kind of condition must be changed. The study constructs the effective systematic work platform on the graduation design, operation of the system platform, it overcomes the serious problem of the graduation design and improves the quality of the skilled talent trained.

\section{CONSTRUCTION OF SYSTEMATIC WORK PLATFORM OF THE GRADUATION DESIGN}

The construction of outside work platform of graduation design, in the school outside, Our college established good cooperation relationships with nearly 20 large and medium-sized enterprises respectively, which are Chongqing Changan automobile Co., Ltd, Chongqing Construction motorcycle Co., Ltd D., Chongqing Jialing group companies establish practice base, at the same time, Southwest aluminum corporation, Chongqing Zongshen group company, Liberation army 6905 factory, Chongqing Huxi motor, Chongqing Sichun microelectronics Co., Ltd, Chongqing Dajiang vehicle general factory, Chongqing Lifan group company and chongqing Micro-electric field park enterprises etc. We established long time cooperation relations with the practical training bases in the order form training, the bases co-constructing, the reforming practice, graduate students employed with the practical training bases. Based on the external practical environment to develop the graduation design, it makes the students' subjects range that are wide very. There are a number design topics of the students graduation designs that have practical significance and more have practical application values, such as " the design of the solar energy fan cap ", " design of the solar energy water heater controller ", " design of the small solar charger ", " design of the solar LED lamp ", " control machine based on single chip dc", and so on, which makes the graduation design to have a definite object, and the goal is more clear, at the same time, the design results have also strong practicability.

"School in the factory " is an important outside practical environment. In the "school", a part of the teaching links are moved to external training base, enterprise's technical personnel combine with the production experience, to explaine the main points of the production process and specific technolgy of the production line and technical processing for the production problem, and the production safety, etc. In such a practical environment, the topics selected more plentiful, such as: "automatic control of the Siemens S7-200 transfer car", "acquisiting circuit of the temperature sensor", " design of some of parts in the industrial robot ", "comparative study of the fuse and circuit breaker", "application of the high speed cutting tool in the 
numerical control processing", "design of the control system of the lifting structure car", "protection principle of the converter gas", "the application of PLC in the emergency generator", etc. The students have summed up the valuable graduation design topic, because difficulty is not greatly, it makes graduation design implementing difficulty is also small relatively, which makes the students to willing independent complete the graduation designs, so as to avoid on the copy of without target.

\section{CONSTRUCTION OF CAMPUS WORK PLATFORM THE GRADUATION DESIGN}

Practical environment of the mechanical and electronic profession group is made by electrical electronic training room, transfer machine installation and debugging training room, maintenance electrician practice room, CAD/CAM training room, frequency converter application training room, fitter training room, nc training room, school-run mechanical processing plant, etc. they cannot be ignored to train the students' practical skills. But the practice process show that the each separate unit and external training base is some relatively independent and individuals operation, they lack coordination and cooperation in training process and training methods of the skilled talents, have not been able to achieve systematic operation for talents cultivated. To improve this kind of condition, the mechanical and electronic sorting creates a system platform on the training and the service under the "double main body" and "the double center".

In the system platform, "double main body" refers to the school and the enterprise as two main body, "the double centers", that are the mechanical and electrical professional training center and mechanical and electrical professional service center. "Double main body" with "the double center" as the two bridge rail, drives effective construction about all kinds of professional skills training and vocational skills service. "The double center" relies on the "double main body", it connects each unit of the vocational training education, and constructs total system working platform of the skilled personnel training and the professional skill servicing.

The mainly members of the double subject and the double center are composed by the industry experts and the "double teachers model" and enterprise technical backbone. In the teaching, the centers carry out regular work on the professional constructed to organize the college professional teachers and the enterprise persons, to carry on the practice investigation, to study industry planning and to sure society needs of the professional talents in regional economic. Then the centers complete following assignments, which are to identify training target of the professional talents, to amend professional cultivating plan, to develop course commonly and coordination teaching in the college-enterprise cooperation such as education work. At the same time, centers make to survey the satisfaction of the training quality for professional talent. Through teaching fusion between in the sole duty teachers and the part-time teachers, it brings into play the specialized technology and the professional skills for these part-time teachers, and makes up the lack of the teaching methods and the teaching theory. In the technical service, centers can be combined with applications of new technology and new equipment in the enterprises. The school-enterprises cooperated to develop teaching training equipments. The measures are applied to make the teaching process that is more closed to the production reality. In the centers working, the college intelligence resources can be full used to develop the necessary equipment and to improve the work efficiently and to promote the industry development for the enterprises.

In the double subject mechanism, the school and the enterprises jointly establish three service center of the hierarchical type (workstation of the training and the service on the common mechanical and electrical equipment, workstation of the training and service on the numerical control technology, the workstation of the training and the service on the automatic production line). In the mechanism runing, we set also up two institutes for the enterprises to provide professional skill training and technical consultation, which are the research institute of the engineering and machinery equipments, and the research institute of the mechanical and electrical engineering applying.

The double centers rely on the double subjects to make the every work in the professional talents trained, while the double subjects transit the double centers to implement a range of effective construction on the training of the professional talents and the service of the professional skills. In the double subject mechanism, the school and the enterprises jointly establish three service center of the hierarchical type (workstation of the training and the service on the common mechanical and electrical equipment, workstation of the training and service on the numerical control technology, the workstation of the training and the service on the automatic production line). In the mechanism run, we set also up two institutes for the enterprises to provide professional skill training and technical consultation, which are the research institute of the engineering and the machinery equipments, and the research institute of the mechanical and electrical engineering applying technology.

The research institute of the engineering and machinery equipment, which researches on the applying technology of the mechanical and electrical engineering, the difficult problems in the vocational skills training education and scientific research are solved, for the school and the enterprises to provide various technical contributions about the design and the consultation and the service. The research institute can also provide the social channels and the actual development ways for the teachers and the 
students in the engineering application of the mechanical and electrical knowledge, and provide effective comprehensive guidance for graduation design and graduation thesis of the students.

The training centers and the service centers of the mechanical and electrical profession under the double subject engage professional skill training, at the same time, they still concurrent functions of the vocational skills servicing. In the servicing process, using " the research institute of the mechanical and electrical engineering technology " and " the research institute of the engineering machinery equipment " to undertake some items on the research and development of the application technology and the technical devices, absorbing excellent students to participate in, the students reform teaching equipments, undertake technology development projects in the enterprise production. Through this ways, the abilities of the students to understand the mechanical structure and the working principle on the mechanical and electrical equipment are enhanced, the students also promote the abilities to engage the equipment installing and testing and maintaining.

The students provide technical service on the electrical equipment maintained for related enterprises in the area, two research institutes organize part of teachers and a number of students to participates, in technical serviced, students learne a lot of technology skills, at the same time, they also accumulate a lot of valuable the graduation design topics, such as: " assembling motor research of the moving robot " "control of the machine tool cutting heat " and so on. The institutes organize the students to participate in various skill competition, not only to enhance theoretical level greatly, and to examina the practical skills, some of the graduation design topics have innovation, such as: " design and control of the two dimensional freedom robot ", "research of the three dimensional freedom robot " and so on, they open practice approach for innovation education. In the double center mechanism, the students actively involved in teacher's scientific research also, in which, they strive to practice and actively to explore, some students bear independently the teachers' scientific researchs, which make quality of the students' graduation design highered, and the results are also more concerned.

\section{ESTABLISH OF SYSTEMATIC EVALUATION} MECHANISM OF THE GRADUATION DESIGN QUALITY

Construction of the evaluation mechanism of the graduation design process, it is a system working platform to determine graduation design topic and to examin graduation design process and to evaluate graduation design achievements. The platform includes: in examination of the graduation design topic selected, applied method is college teacher primarily judging and enterprise part-time teachers futher examining; In the graduation design process inspecting, applied method is combined the graduation design lengthways review (nosocomial) with graduation design crosswise review (external practical environment); For evaluation of the graduation design results, combined the students batch with random inspection, in the more practical, applied method is respondent " factory in the school " to evaluate graduation design results. These make graduate design system of the electro mechanical profession that is more effectively.

\section{CONSTRUCTION OF THE INFORMATION RESOURCE PLATFORM OF THE GRADUATION DESIGN}

Since 2008, the ministry of education starts status data collected platform on the talent cultivation work of the higher vocational college, the status data became the main source evaluated information [3][4][5]. But, it is still difficult to true reflect professional situation of students. According to this situation, "double subject" launched construction of the digital campus project in the "1025" planning, integrated the network of OA office system, human resource system, financial management system, teaching management system, student management system, graduate employment management system and diagram management systems, such as information environment. In the digital system, the students graduation design and the design quality and the teachers evaluation and the enterprise satisfaction are effective evaluating data, they are important indicators on the professional talent training quality.

\section{CONCLUSION}

Through construction of the systematic working platform on the graduation design, it solves the serious problems in the graduation design, improves education system and the professional training mode of the mechanical and electrical professional, the students improve the practical skill through develop design in the environment to suitable for their professional skills opened and professional service capacity enhanced, their professional skills and innovation achievements have better outstanding.

\section{ACKNOWLEDGMENT}

This work is supported by The China's Chongqing education committee (PN: CJ113228).

\section{REFERENCES}

[1] Zhiqun Zhao: Curriculum Development Guidelines of Vocational Education and Industry-Led Integrated (Qinghua University Press. China 2009).

[2] Youru Xie, Kedong Li. Education Technology Research Foundation. (Higher Education Press. china 2006)

[3] Qianwei Zhang. Information literacy and education of the information literacy. journal of electrochemical education research. No3, (2001). p. 86

[4] Xiaomei Zheng. Overview of development mode on the foreign vocational education curriculum. Gansu Journal of Education College. No1, (2003). p44.

[5] Zhixian Zhong. Design of the resources, tools and the evaluation under learning environment. Opening Education Research No3 (2005). p112. 